\title{
OUTRO PARADIGMA PARA O DIREITO: REFLEXÕES A PARTIR DA TEORIA DA DESCONSTRUÇÃO DE JAQUES DERRIDA E DA VIDA CONCRETA DE ENRIQUE DUSSEL
}

\author{
Diogo Bonfim Fernandez* \\ Larissa Ambrosano Packer*
}

\begin{abstract}
RESUMO
O texto utiliza-se da teoria da desconstrução como postura filosófico-epistemológica importante para se entender o fenômeno jurídico enquanto algo aberto, complexo e multifacetado. Coloca em cheque, a teoria desconstrutivista, a figura do "operador" de um direito posto, fechado e acabado. Ao contestar esta racionalidade branca, adulta, possuidora, carnívora - universal e una - que (im)põe os horizontes do posto, a teoria derridiana assume as aporias do fundamento, da regra e do saber. $\mathrm{O}$ que foi revelado pela razão e estatizado pelo ordenamento não é o verdadeiro, o correto e único apto a reger e falar sobre a realidade social. Surge assim necessariamente o Outro, o diverso, o que até então era o não-ser ou não-sujeito, desenvolvido pela filosofia da libertação de Enrique Dussel. É na busca por este vir-a-ser do que é negado e sonegado que surge a figura dos construtores de um direito plural e estruturalmente aberto, público e inesgotável.
\end{abstract}

Palavras-chave: Desconstrução; Outro; aporias; vida concreta; justiça.

SUMÁRIO: INTRODUÇÃO; 1 DERRIDA E A JUSTIÇA; 1.1 A APORIA DA FORÇA; 1.2 JUSTIÇA E DESCONSTRUÇÃO; 2 AS APORIAS E A VIDA CONCRETA; 2.1 PRIMEIRA APORIA: A EPOKHÉ DA REGRA; 2.2 SEGUNDA APORIA: A ASSOMBRAÇÃO DO INDECIDÍVEL; 2.3 TERCEIRA APORIA: A URGÊNCIA QUE BARRA O HORIZONTE DO SABER OU A BUSCA POR CERTEZAS; 3 CONSIDERAÇÕES FINAIS; 4 REFERÊNCIAS.

\footnotetext{
${ }^{*}$ Mestrando em direito pela UFPR - diogobonfim@yahoo.com.br

** Mestranda em direito pela UFPR - laricapacker@hotmail.com
} 


\section{INTRODUÇÃO}

O tema a ser tratado neste artigo é dos mais caros à filosofia política e jurídica, sendo tratado desde os clássicos até os dias de hoje. Em Platão e Aristóteles a questão da justiça já se colocava na centralidade das discussões; no período medieval e na modernidade que se seguiram continuou a ser interrogada e atualmente, mais precisamente no presente texto, ela se repete; sem que isto signifique uma evolução sobre a enorme problemática que carrega.

Mas será que o tema já não foi gasto pelo incessante refletir a seu respeito? Ainda poder-se-ia falar algo novo ou de interesse geral a seu respeito, dado que grandes pensadores em diversas sociedades sobre ele já se debruçaram?

A resposta dada pela filosofia contemporânea é que a problemática da justiça merece nossa atenção, pois justamente a repetição de todo o esforço, o sempre escrever sobre ele, o persistir no tempo e a insistência do homem em perscrutá-lo, demonstram, para além da condição de não esgotado, acima de tudo, a sua importância e impotência diante das realidades concretas. Não que o leitor tenha diante de si um excerto de envergadura que seja capaz de dar conta de tamanha problemática, longe disso, o que se pretende é a abordagem do tema a partir de outro lugar para além dos horizontes que encerram a totalidade do que seja o hoje.

Esta abordagem é encetada por um pensador contemporâneo, um "crítico" da modernidade, que tem como principais influências as novidades trazidas pela reviravolta lingüística. Trata-se de Jacques Derrida e a obra Força de Lei, que traz importantes elementos para se pensar o direito e a justiça sob outras bases filosóficas e epistemológicas, para além do pendular movimento entre as correntes juspositivistas e jusnaturalistas sob as quais se encerrou o problema jurídico nos séculos.

Nessa sua conferência de abertura do colóquio organizado na Cardozo Law School em $1989^{1}$, o filósofo encaminhará a temática da justiça a partir de um

\footnotetext{
${ }^{1}$ DERRIDA, Jacques. Força de lei: o fundamento místico da autoridade. São Paulo: Martins
} 


\section{OUTRO PARADIGMA PARA O DIREITO: REFLEXÕES A PARTIR DA TEORIA DA DESCONSTRUÇÃO DE JAQUES DERRIDA E DA VIDA CONCRETA DE ENRIQUE DUSSEL}

questionamento da força da lei e do direito. Pensa o direito a partir da exposição de suas aporias e enquanto texto (regra, norma, decisão) em busca de realização da justiça, apontando a inevitável (des)construção da própria estrutura interna da normatividade posta.

O presente texto traz também um aporte na Filosofia da Libertação de Enrique Dussel ao apontar o momento ético-material da vida concreta enquanto fundamento necessário neste incessante movimento de abertura e fechamento do direito em busca de justiça e democracia. Intenta, desta forma, mostrar a necessidade deste movimento de desconstrução realizar o descobrimento do Outro, negado e sonegado, como o próprio ser Latino Americano e brasileiro.

\section{DERRIDA E A JUSTIÇA}

\subsection{A APORIA DA FORÇA}

No texto Força de Lei, Jacques Derrida pergunta pela força da lei, com este questionamento o autor busca compreender o que faz com que uma lei seja aplicada. Derrida enceta o caminho de uma resposta a partir daquilo que no inglês se diz como "enforceability". Esta remissão à língua inglesa é esclarecedora, pois com isso se mostra um dos aspectos envoltos na aplicabilidade de uma lei: a aplicação de uma lei exige força. Esta tomada em sentido físico mesmo, tal como Kant postulou na sua teoria do Direito: "(...) o direito apóia-se (...) no princípio da possibilidade de uma coação exterior". Facilmente se é levado juntamente com Kant a perguntar pela legitimidade da força, - 'Gewalt', em alemão - por que a força é justa? Em outras palavras, o que justifica o uso da força?

Fontes, 2007, p. vii. 
O mesmo pode-se encontrar em Pascal. No fragmento deste último trazido por Derrida, lê-se: "Justiça, força - É justo que aquilo que é justo seja seguido, é necessário que aquilo que é mais forte seja seguido" ${ }^{2}$. A primeira parte desse aforismo é tautológica, diz apenas que o justo deve ser seguido porque é justo; a lei deve ser obedecida pelo fato de ser justa, como se a justiça da lei justificasse a sua aplicabilidade. A lei é justa e a justiça é a aplicação da lei. Na segunda parte do aforismo, encontra-se a idéia de que pra que a justiça seja realizada, para que a lei seja obedecida, necessita-se de força; fica claro que justiça e força andam juntas. E o que justifica a força presente na lei é a justiça.

Assim, a força não é algo que se acrescenta ou não ao direito, ela faz parte da sua essência. Não há direito sem força.

Todavia, quando Kant menciona o uso da força, ainda não se solucionou de todo o problema, e o mesmo pode se dizer da explicação de Pascal, haja vista que afirmar que aplicar a lei justa é fazer é justiça é incorrer em circularidade ${ }^{3}$, em falta de fundamentação, em falta de razões, em aporia.

Resta ainda a pergunta pela força de uma lei, e também a pergunta pela força da força e assim indefinidamente. Não se recorreria a outra força física para justificar o uso da primeira, pois se cairia na mesma aporia, em regressão ao infinito. A partir de Derrida pode-se enxergar um outro modo de força que não seja físico. $\mathrm{O}$ autor afirma: "No começo da justiça, terá havido o logos, a linguagem ou a língua, mas isso não é necessariamente contraditório com outro incipit que dissesse: 'No começo, terá havido a força'. O que se deve pensar é, pois, esse exercício da força na própria linguagem". ${ }^{4}$

Neste trecho, Derrida aponta para um outro tipo de força que não é físico, ele se refere à força da linguagem. Logo, poderíamos pensar a justificativa/justiça de uma

${ }^{2}$ Ibidem, p. 18.

${ }^{3}$ KOZICKI, Katya. A interpretação do direito e a possibilidade da justiça em Jacques Derrida. In: FONSECA, Ricardo Marcelo (org.). Repensando a teoria do Estado. Florianópolis: Fundação Boiteux, 2005. p. 134.

${ }^{4}$ DERRIDA, op. cit., pg. 17-18. 


\section{OUTRo PARAdigma PARA O DiREITO: REFleXões A PARTIR DA TEORIA DA DESCONSTRUÇÃO DE JAQUES DERRIDA E DA VIDA CONCRETA DE ENRIQUE DUSSEL}

força física a partir da linguagem; seria esta capaz de apresentar argumentos ou razões que justificassem o uso da força ou a mostrassem como legítima? Segundo Derrida, isto não é possível, pois não temos como apresentar razões para dizer que um ato de força que funda, instaura e aplica a lei é justo ou injusto. Ele afirma:

Ora, a operação de fundar, inaugurar, justificar o direito, fazer a lei, consistiria num golpe de força, numa violência performativa e, portanto, interpretativa que, nela mesma, não é nem justa nem injusta, e que nenhuma justiça, nenhum direito prévio e anteriormente fundador, nenhuma fundação preexistente, por definição, poderia nem garantir nem contradizer ou invalidar ${ }^{5}$.

Em outras palavras e em última instância, não há como legitimar o uso da força, não há como dizer que uma força ou uma lei é justa e tampouco dizer que é injusta recorrendo-se a noções anteriores ao direito ou à linguagem. Nessa tentativa, o discurso encontra seu limite ${ }^{6}$. Tentar falar de ou estipular um critério preexistente ao ato fundador da lei e que justificasse a sua aplicação mediante a força é tentar extrapolar limites. O limite aqui não é pensado como o que separa uma coisa de outra, mas como aquilo que impõe barreiras e que não podem ser transpostas; o que está em jogo aqui é a noção de finitude. A impossibilidade de transpô-lo marca a impossibilidade de se falar; não se pode tentar expor através da linguagem um critério último e definidor de justo ou injusto, sobre isso devemos nos calar e nos silenciar.

Derrida fortalece essa afirmação a partir de Montaigne: "Ora, as leis se mantêm em crédito não porque elas são justas. É o fundamento místico da autoridade, elas não têm outro...". O termo místico usado aqui por Montaigne diz respeito justamente à falta de fundamento, o qual é impossível de ser demonstrado e destarte ilusório e irreal.

Toda a tentativa de pensar a justiça identificada com a lei, direito e a força inerente a este, resulta em aporia, numa falta de fundamento e razões.

\footnotetext{
5 Ibidem, p. 24.

${ }^{6}$ Ibidem, p. 25.
} 


\subsection{JUSTIÇA E DESCONSTRUÇÃO}

Dado isso, o autor se propõe a tarefa de pensar a justiça não mais com relação ao direito, mas separada e descolada do direito: "Quero logo insistir, para reservar a possibilidade de uma justiça, ou de uma lei, que não apenas exceda ou contradiga o direito, mas que talvez não tenha nenhuma relação com o direito, ou mantenha com ele uma relação tão estranha que pode tanto exigir o direito quanto excluí-lo"7 .

Essa outra forma a que Derrida se refere é a maneira de pensar a justiça a partir da desconstrução. Essa última, entendida de forma não-definitiva, seria uma desestabilização de teorias e construtos teóricos por meio da denunciação de suas aporias, desmascaramento de seus antagonismos e contradições, marcada por uma reinterpretação e releitura de tudo o que nos foi legado historicamente na filosofia e no direito. Sendo que tudo o que nos foi legado historicamente o foi através da escrita, a desconstrução é a releitura dessas concepções herdadas, que, em razão de terem sido construídas em determinado contexto e historicamente datadas, podem ser desestabilizadas e reconstruídas, relidas ${ }^{8}$.

O que, pensando no caso da nossa época, engloba a desconstrução de alguns pilares da modernidade tais como a noção de sujeito, consciência, sujeito de direito, sujeito responsável, a oposição entre convenção e natureza ${ }^{9}$, em suma, é a investida contra uma metafísica antropocêntrica que alçou o homem ao lugar de fundamento e fim último sobre a terra.

Ora, se pensarmos que tanto o direito atual quanto a noção de justiça que nos foi legada, qual seja, a da identidade entre justiça e direito, estão pautados nas teses desestabilizadas e desmascaradas pela desconstrução, seria sensato, à primeira vista,

\footnotetext{
${ }^{7}$ Ibidem, p. 8 .
}

${ }^{8}$ Eis por que Derrida aponta a importância da linguagem logo no início da apresentação ao dizer: "Essa questão da língua (...) estará certamente no cerne daquilo que eu desejaria de lhes oferecer à discussão". Ibidem, p. 7.

\footnotetext{
${ }^{9}$ Ibidem, pg. 12-13.
} 


\section{OUTRO PARAdigma PARA O DIREITO: REFLEXões A PARTIR DA TEORIA DA DESCONSTRUÇÃO DE JAQUES DERRIDA E DA VIDA CONCRETA DE ENRIQUE DUSSEL}

pensar que a relação que a desconstrução guarda com o direito e com a justiça seria uma relação de desconstruir o direito e também a desconstrução da justiça e de suas regras tal como conhecemos tradicionalmente. ${ }^{10}$

Para fugir dessa situação e então poder estabelecer relações entre a desconstrução e a justiça, é necessário diferenciar que o direito é algo posto, herdado, criado por meio da escrita e datado, "construído por camadas textuais interpretáveis e transformáveis", que pode ser apreendido e conceituado, que permite destacar o legal do ilegal, que é medível e manipulável; por outro lado, a respeito da justiça, Derrida afirma: "(...) não se pode falar diretamente da justiça, tematizar ou objetivar a justiça, dizer 'isto é justo' e, ainda menos, 'eu sou justo', sem trair imediatamente a justiça(...)"11. Isto é, não se pode tematizar a justiça, ela não é um conceito, dado, pronto e acabado, pois não existe a justiça enquanto tal, existindo separadamente de nós homens alhures (uma concepção substancialista), a ser alcançada e conhecida, e por não ser passível disso, por ela não estar pronta é que ela não pode ser desconstruída.

O direito por estar posto, sedimentado na linguagem e na escrita, é algo que pode ser desconstruído; a justiça não se encontrara pronta no direito e tampouco fora dele e além dele, por não ter esse caráter, não pode ser desconstruída, ela é indesconstruível. A desconstrução não desconstrói a justiça, a desconstrução é a justiça.

A desconstrução como modo de se apresentar contradições e apontar aporias, deixa as nossas concepções na falta de fundamento, deixa-as em aberto para ao mesmo tempo fechá-las; em outras palavras, desconstrói respostas dadas anteriormente e herdadas por nós e põe novas respostas, as quais nunca são definitivas, totalizantes e universais; o que é "construído" nunca é definitivo, pelo contrário, já traz em si a possibilidade de ser desconstruído. Neste contexto, pelo fato de não se tentar postular

\footnotetext{
${ }^{10}$ Ibidem, p. 26.

${ }^{11}$ Ibidem, p. 17.
} 
algo eterno e imutável, a justiça se manifesta mais propriamente como puro movimento de desconstrução cujos resultados nunca são fechados e acabados, sendo sempre algo por vir e por se realizar.

Derrida nos diz que a justiça é um apelo à justiça, ela é sempre algo por vir e que nunca se completa, mas que, no entanto, não pode nunca sair debaixo de nossas vistas, sob pena de cairmos num irracionalismo e assentir que, uma vez que não existem respostas últimas e definitivas para os problemas do homem, tudo é possível e já não há sentido em nos guiarmos por algo. Pelo contrário, contra os riscos substancialistas (da existência de uma justiça para fora ou além do direito) e irracionalistas (que não há nada e que tudo vale) há algo que sustenta a esse movimento, esse algo é o próprio impulso, vontade de justiça. Segundo o autor: "Pois, afinal, onde a desconstrução encontraria sua força, seu movimento ou sua motivação, senão nesse apelo sempre insatisfeito(...)". ${ }^{12}$

Se ao pensarmos a justiça colada ao direito nos vimos em aporia, quando a pensamos a partir da desconstrução, e, portanto, já descolada dele, de certa forma também estamos em aporia, pois não se postula a existência de fundamentos sólidos e inabaláveis, porém, a peculiaridade da desconstrução é que ela assume essa falta de fundamento e a utiliza de tal forma que sempre permite o novo e a mudança.

Concebendo a justiça como esse nada, este por vir que não é o futuro; mas um impulso ou vontade de transformação que está sempre acolá; esta não pode ser construída (desconstruída) e presentificada, ou seja, manipulada, calculada e estabilizada. Este papel de fixação, estruturação do presente a fim de assegurar alguma calculabilidade ou estabilidade das relações em determinado momento pertence ao direito, à lei. Deste modo o direito, para não se apresentar como mera regulação, conservação e dominação, deve, ao fechar-se, abrir-se. Ao colocar-se enquanto determinado conteúdo de sentidos em textos legais, deve-se admitir as $n$ possibilidades de sentidos negadas para poder presentificar-se.

\footnotetext{
${ }^{12}$ Ibidem, p. 39.
} 
OUTRO PARADIGMA PARA O DIREITO: REFLEXões A PARTIR DA TEORIA DA DESCONSTRUÇÃO DE JAQUES DERRIDA E DA VIDA CONCRETA DE ENRIQUE DUSSEL

\section{AS APORIAS E A VIDA CONCRETA}

\subsection{PRIMEIRA APORIA: A EPOKHÉ DA REGRA OU A APORIA DA FUNDAMENTAÇÃO}

Este movimento de abertura do posto ou do dado se dá, segundo o autor, através da interpretação e aplicação ("enforceability") do direito pelos "construtores do direito" e não por seus meros "operadores" como quer a tradição positivista. Já que o texto conterá sempre aporias que mostrarão que um significante possui inúmeras significações, qualquer texto pode querer dizer algo que escapa a qualquer leitura convencional.

Deste modo, a partir de uma regra positivada ou uma lei geral, a decisão do juiz para ser justa ou responsável, deve constituir-se em um julgamento fresco ("fresh judgment"). Este novo julgamento pode ou deve repetir algo conforme lei preexistente, mas enquanto exercício da justiça como direito, esta interpretação deve ser reinstauradora, criativa, como se não existisse lei anteriormente e o juiz inventasse ele mesmo em cada caso uma regra. Assim, a decisão deve ser ao mesmo tempo "regrada e sem regra, conservadora da lei e suficientemente destruidora ou suspensiva da lei para poder reinventá-la em cada caso" ${ }^{13}$.

O caso concreto demanda soluções absolutamente novas, também precárias e contingentes, pois um novo caso ou decisão que se textualiza remete a novas reinterpretações e criações. Nenhuma regra existente pode garantir a complexidade das questões que se colocam e as múltiplas interpretações que se podem gerar. Interpretações que variam diatópica e diacronicamente segundo a vida concreta de cada sujeito (segundo sua classe social, suas tradições e culturas) como vai desenvolver Enrique Dussel em sua Ética da Libertação ${ }^{14}$.

\footnotetext{
${ }^{13}$ Ibidem, p. 44.

14 DUSSEL, Enrique. Ética da libertação - na idade da globalização e da exclusão. Petrópolis: Vozes, 2000.
} 
Apesar de os sistemas legais modernos dizerem-se auto-referentes e autovalidantes, ao partir de uma fundamentação positivista interna - Grundnorm em Kelsen ou regras de reconhecimento em Hart, por exemplo - ou ainda buscarem fundamentações exteriores em princípios imutáveis e eternos - jusnaturalistas - o que há é um fundamento místico, uma aporia, insuscetível de avaliação, ou seja, o que há é uma ausência de fundamento do direito. Aqui o problema se o direito é justo ou injusto não se coloca, está violentamente resolvido enquanto aporia ${ }^{15}$, ou de outra forma, "vale por que vale" sob pena de se recorrer ao infinito.

Ao se colocar (construir) enquanto sistema escrito ou estrutura regrada, e sem qualquer fundamento, o direito ou a justiça como direito, pode ser desconstruído, e isto é uma boa notícia para Derrida. É nesta abertura que o direito pode perseguir a justiça e a sociedade a democracia; o reconhecimento da pluralidade, do conflito, do Outro é o movimento que pode permitir ao direito a busca por justiça.

Deste modo, a regra se põe como a primeira aporia para a perspectiva desconstrutivista de Derrida, já que nenhum ordenamento que se pretende fechado e calculado pode gerar decisões justas ao caso concreto a partir de uma "parasitagem irredutível pela mecânica ou pela técnica" ${ }^{16}$. Por outro lado, também não é justa uma decisão que parta de nada, de nenhuma regra abstrata, como se nela não contivesse nenhum sentido, ou se então o juiz simplesmente não decidir e suspender sua decisão.

Colocada a questão desta forma, a regra apresenta-se como aporia: carrega experiências históricas de gerações, assim como se abre diante do caso concreto ao devir, ao futuro, ao Outro para além dos horizontes do hoje, enfim, à justiça. Mas ao abrir-se para realizar a justiça, como direito deve fechar-se, materializada a decisão nova como regra, novamente se fecha para ser aplicada, o que simultânea e dialeticamente causa sua abertura às incalculáveis interpretações e possibilidades. E esta é a aporia da regra. em debate.

\footnotetext{
${ }^{15}$ Reconhecimento por parte de todos os interlocutores da impossibilidade de definir a noção
} ${ }^{16}$ DERRIDA, op. cit., p.45. 


\section{OUTRO PARADIGMA PARA O DIREITO: REFLEXões A PARTIR DA TEORIA DA DESCONSTRUÇÃO DE JAQUES DERRIDA E DA VIDA CONCRETA DE ENRIQUE DUSSEL}

\subsection{SEGUNDA APORIA: A ASSOMBRAÇÃO DO INDECIDÍVEL}

O indecidível é o momento anterior à aplicação, à materialização da regra. É o nada (ou o tudo), são as múltiplas possibilidades, é o incalculável, aquilo que foge a um desenvolvimento contínuo de um processo calculável. Pode-se em outras palavras afirmar, que o momento do indecidível é a loucura para a estrutura vigente. Não é possível sua presentificação, sua realização ou justeza; apenas uma decisão é justa, é medida. Esta decisão não precisa referir-se a um sujeito ou um juízo que a propõe; já que "um sujeito nunca pode decidir nada", "a decisão é um acidente periférico" ${ }^{17}$. Ou seja, o sujeito não decide porque não detém a possibilidade de cálculo sobre as conseqüências infinitas de uma decisão e o poder de manter essa decisão. Da decisão os sentidos se proliferam, a reinterpretação é pública, aberta, inesgotável.

Deste modo, passada a prova da indecidibilidade - se é que este momento ocorreu, já que de hábito positivista o operador crê na neutralidade e apenas aplica a regra geral - ela já se estruturou enquanto regra, passível, portanto, de se desestabilizar ou desestruturar. Derrida coloca então, a permanência do indecidível como um "fantasma" essencial que paira sobre qualquer decisão. Essa fantasmaticidade revela que toda estrutura, fixação, decisão contém sua desconstrução. A presença é a afirmação da ausência, a construção a afirmação da desconstrução - é este indecidível enquanto momento essencial que garante a justiça de uma decisão. "Sua fantasmaticidade desconstrói do interior toda garantia de presença, toda certeza ou toda pretensa criteriologia que nos garanta a justiça de uma decisão". ${ }^{18}$

Esta segunda forma da mesma aporia, o indecidível, deve conservar-se vivo, essencial em qualquer decisão pra desconstruir do interior toda presença, certeza e criteriologia postas por um antropocentrismo europeu-branco-carnívoro, que a tudo domina e tudo submete. ${ }^{19}$ Desta forma, a cultura jurídica desenvolvida sob o pendular

\footnotetext{
${ }^{17}$ Ibidem, p.48.

${ }^{18}$ Idem.

${ }^{19}$ É o que Derrida coloca como a axiomática subjetal da responsabilidade, da consciência, da
} 
movimento entre jusnaturalistas e juspositivistas fechou-se em realidade a uma mesma lógica estática e una, como se o ordenamento tivesse colocado a sociedade em ordem, como uma utopia realizada.

\subsubsection{O Direito e o paradigma da consciência}

O que o paradigma moderno (im)põe é que a razão - branca, adulta, possuidora, carnívora (para Derrida) - universal e una, enquanto imperativo categórico, ordena a realidade e põe determinada norma de conduta que deve ser seguida, já que se atingiu o ápice do desenvolvimento humano. O que foi revelado pela razão e estatizado pelo ordenamento é o verdadeiro, o correto e único apto a reger e falar sobre a realidade social.

O que se verifica é que o pensamento jurídico moderno sempre se estabeleu, independentemente da corrente do pensamento, apartir de abstrações realizadas pela razão, ou seja, a partir de um plano ideal através do qual se investiga de forma lógicoformal o sistema instituído - afastando-se de sua base material - do ser social de onde realmente brota o direito. Seja elegendo enquanto objeto de investigação leis universais ideais estáticas e absolutas (jusnaturalismo); a lei estabelecida pelo Estado (Escola da Exegese), os fatos sociais expressos em regiões abstratas como o espírito coletivo de um povo, apreendido como os fatos naturais, a partir de método rígido e formal (Escola histórica), a norma fundada na norma - Grundnorm - (Normativismo Kelseniano) etc. O pensamento científico jurídico sempre se forjou no plano de um idealismo lógico, desconectado de sua ambiência histórica. Já que a única "experiência" ou objeto observável admitido pelo positivismo são os textos legais, as

intencionalidade, da propriedade que comanda o discurso jurídico atual; classificando como uma grosseria teórica essa tentativa de perseguir a certeza, o cálculo ou a singularidade enquanto a justiça. Se há desconstrução de toda pretensão à certeza de uma justiça presente, a justiça é referida a outro, a uma singularidade outra, irredutível porque devida a outro, não à identidade, ao sujeito, ao posto. Ibidem, pg. 48-49. 


\title{
OUTRO PARAdigma PARA O DIREITO: REFLEXões A PARTIR DA TEORIA DA DESCONSTRUÇÃO DE JAQUES DERRIDA E DA VIDA CONCRETA DE ENRIQUE DUSSEL
}

estruturas lógicas da norma jurídica. Tão ideal é o objeto do empirismo positivista quanto do racionalismo naturalista ${ }^{20}$. Ambas as vertentes - direito natural e o positivismo - forjaram um "falso dilema" - como diz José Eduardo Faria. Seja Deus, a natureza, a idéia, a razão humana ou a norma o fundamento de validade do direito, essas correntes

\begin{abstract}
assumem uma postura acentuamente metafísica no trato do problema jurídico, ora encarando-o como expressão de princípios ideais absolutos, existente não se sabe bem onde; ora considerando-o um mero reflexo dos fatos sociais que seriam captados tais quais são na realidade (...) a metafísica de todos esses posicionamentos consiste precisamente no fato de eles isolarem os termos da relação cognitiva, dando prioridade seja ao sujeito, seja ao objeto, e consequentemente desvirtuando a compreensão do processo de elaboração do conhecimento, a qual só pode ser eficaz se localizada dentro da relação que se opera entre esses termos, ou seja, entre o sujeito e o objeto ${ }^{21}$.
\end{abstract}

A filosofia e ciência do direito, calcada no positivismo lógico - atomista, neutro, dogmático e racionalista - forjam-se como utopia realizada, ou seja, tendo instituído um pensamento tradicional, permanece agora fora da dinâmica da história, "negando as incertezas e o novo que continuamente emergem de sua tessitura"22 num movimento pendular entre o que se poderia chamar, paradoxalmente de empirismo idealista e o idealismo abstrato.

O que a teoria da desconstrução desenvolvida por Derrida vai denunciar é esta absoluta impossibilidade de se resolver a relação cognitiva em torno do uno e do estático, assumindo assim a multiplicidade e a dinamicidade da realidade. Assim, o indecidível que paira como um fantasma sobre qualquer texto que se (des)constrói, trata-se da assunção da contingência, do dialético movimento da condição humana em sua relação de (des)construção sob e na natureza.

\footnotetext{
${ }^{20}$ MACHADO, Antonio Alberto. Ensino jurídico e mudança social. Franca: Unesp-FHDSS, 2005, p.50.

${ }^{21}$ MARQUES NETO,Agostinho Ramalho. Introdução ao estudo do direito: conceito, objeto, método. 2. ed. Rio de Janeiro: Forense, 1990, p.53.

${ }^{22}$ WARAT apud MACHADO, op. cit., p. 56.
} 
Aplicando-se tal superação epistemológica em não se perseguir um fundamento à técnica jurídica, tem-se que as regras postas são meros parâmetros histórico-institucionais a serem observados, porém cada caso concreto coloca a necessidade da abertura. O juiz, o ministério público e diversos órgãos estatais juntamente com a sociedade, as comunidades e sujeitos atingidos em seus direitos principalmente os de natureza coletiva e difusa que não encontram recepção adequada pelo Código de Processo Civil - devem promover debates públicos, audiências e outros instrumentos de mediação que concebam o espaço público como algo aberto e em dinâmica (des)construção pelos $n$ sujeitos de direito. E não algo fechado e pronto, a ser conservado e aplicado para se garantir a ordem e o progresso já alcançados. A democracia e a justiça para a teoria da desconstrução é este movimento aporético do devir, do acolá. Mas quem são os sujeitos desta desconstrução? Esta abertura é suficiente para uma mudança paradigmática do direito para além dos horizontes do hoje?

\subsection{TERCEIRA APORIA: A URGÊNCIA QUE BARRA O HORIZONTE DO SABER OU A BUSCA POR CERTEZAS}

Um horizonte, como indicado em grego, é ao mesmo tempo a abertura e o limite da abertura que define ou um progresso infinito ou uma espera ${ }^{23}$. A justiça não espera, não permite a busca infinita por conteúdos e formas que possam justificá-la. A justiça cobra o momento da decisão, que é finito e de urgência e precipitação, não é conseqüência de saber teórico acumulado. A decisão marca sempre a interrupção da deliberação que a precede.

O instante da decisão é uma loucura, como coloca Kierkegaard, já que deve "rasgar o tempo e desafiar as dialéticas"; é o momento de definir, fixar, presentificar

\footnotetext{
${ }^{23}$ DERRIDA, op. cit., p. 51.
} 


\section{OUTRo PARAdigma PARA O DiREITO: REFleXões A PARTIR DA TEORIA DA DESCONSTRUÇÃO DE JAQUES DERRIDA E DA VIDA CONCRETA DE ENRIQUE DUSSEL}

em detrimento da infinitude das possibilidades do conhecimento. Nas palavras do autor, "a decisão é sempre finita, por mais tarde que chegue, é decisão de urgência e precipitação, agindo na noite do não-saber e da não-regra. Não da ausência de regra ou de saber, mas na re-instituição da regra, que por definição, não é precedida de nenhum saber e de nenhuma garantia como tal" ${ }^{24}$. Assim toda decisão que se põe seja regra instituidora ou decisão baseada em convenção anterior - carrega a aporia do saber que a precede.

Assim a desconstrução em Derrida não se apresenta como um mero movimento de aniquilação do velho, de negação do que está aí; mas a afirmação de diversas (des)construções possíveis diante de uma construção, de um texto, de uma norma. É impossível se construir sem desconstruir, é impossível só desconstrução, por isso é urgente que se construa negando uma infinidade de outras possibilidades, este é o movimento de justiça, de devir ou de desconstrução - a própria construção. Para o direito construir-se é necessário resolver-se acerca do fundamento, trata-se de violência eruptiva, de pré-aceitação.

Essa irredutibilidade do instante da decisão, dessa irreflexão ou inconsciência se dá pelo caráter performativo ${ }^{25}$ dos atos de linguagem, ou seja, o agir sobre o interlocutor e sobre o mundo circundante que constitui o ato de falar. Este caráter performativo carrega uma violência eruptiva, uma pré-aceitação ou convenção, a força, e as aporias de fundamento do direito.

As decisões "enforceability" são atos performativos que carregam esta violência ou pressuposto de aceitabilidade. Os enunciados constatativos apóiam-se nessa justiça pressuposta da estrutura performativa do sistema jurídico, por exemplo. Se estes constatativos se adequam ao enunciado performativo são válidos, verdadeiros,

\footnotetext{
${ }^{24}$ Idem.

${ }^{25}$ Um enunciado constatativo descreve ou relata um estado de coisas, e que, por isso, se submetem ao critério de verificabilidade, isto é, podem ser rotulados de verdadeiros ou falsos. Um enunciado performativo é um ato de linguagem que faz, que indica uma ação, trata-se de enunciado que não descreve, não relata, nem constata absolutamente nada.
} 
legítimos ou para Austin ${ }^{26}$ felizes.

O que existe é um transbordamento do performativo por conta do adiantamento excessivo da interpretação, da urgência e precipitação estrutural da justiça - em forma de decisão ou lei -, portanto a justiça não tem horizonte de expectativa, uma substância. O que há é esta fome, esta urgência, este impulso pelo acolá, pelo por vir, a justiça é esta abertura de acontecimentos de transformação, refundição ou refundação do direito e da política.

A justiça é o que excede, transborda aos cálculos, programas, regras e antecipações. "Uma experiência de alteridade absoluta, é inapresentável, mas é chance do acontecimento e a condição da história" ${ }^{27}$

No entanto, Derrida adverte que este impulso de resignificações, desconstruções geradas pelo movimento incessante pelo novo, pode ser apropriado pelo mais perverso cálculo. Devendo assim, serem discutidos e politizados os conteúdos da decisão, "pois abandonada a si mesma, a idéia incalculável e doadora da justiça está sempre mais perto do mal". ${ }^{28}$

"Esse excesso da justiça sobre o direito e sobre o cálculo, esse transbordamento do inapresentável sobre o determinável, não pode e não deve servir de álibi para ausentar-se das lutas jurídico-políticas, no interior de uma instituição ou de um Estado"29."Esta justiça incalculável manda calcular" ${ }^{\prime 30}$. Não há garantias contra

${ }^{26}$ A Teoria dos Atos de Fala surgiu no interior da Filosofia da Linguagem, no início dos anos sessenta, tendo sido, posteriormente apropriada pela Pragmática. Filósofos da Escola Analítica de Oxford, tendo como pioneiro o inglês John Langshaw Austin (1911-1960), seguido por John Searle e outros, entendiam a linguagem como uma forma de ação ("todo dizer é um fazer"). Passaram, então, a refletir sobre os diversos tipos de ações humanas que se realizam através da linguagem: os "atos de fala", (em inglês, "Speech acts"). Austin: "dizer é transmitir informações, mas é também (e sobretudo) uma forma de agir sobre o interlocutor e sobre o mundo circundante". Inicialmente, Austin (1962) distinguiu dois tipos de enunciados: os constatativos e os performativos. Disponível em: http://www.filologia.org.br/viiifelin. Acesso em 28 maio 2008.

\footnotetext{
${ }^{27}$ DERRIDA, op. cit., p. 55.

${ }^{28}$ Idem.

${ }^{29}$ Idem.

${ }^{30}$ Idem.
} 


\section{OUTRO PARAdigma PARA O DIREITO: REFLEXões A PARTIR DA TEORIA DA DESCONSTRUÇÃO DE JAQUES DERRIDA E DA VIDA CONCRETA DE ENRIQUE DUSSEL}

o risco desta abertura do apelo à justiça. Apesar da justiça, para a desconstrução, ser a única coisa verdadeira, esse transbordamento tem de ser previsto e calculado, para ser mais justo, cabível, contextualizado.

Assim, Derrida coloca o repensar dos espaços que isolam o conhecimento nele mesmo. É preciso negociar o incalculável para além do lugar onde estamos, para além das zonas já definidas da moral, política e direito, para além do nacional e internacional; público ou privado, ou seja, desconstruir o que se é para poder calcular o mais longe possível do agora. Realizar o desaprender do que nos impuseram ser.

É preciso que o campo jurídico seja repensado, para além dos territórios hoje identificáveis da jurídico-politização, outras zonas devem abrir-se constantemente, que podem a primeira vista, parecer zonas secundárias ou marginais. Ao politizar-se determinada questão há uma necessidade de reinterpretação dos próprios fundamentos do direito, para além do cálculo até então vigente. $\mathrm{O}$ autor coloca os casos da Declaração dos direitos do homem, da abolição da escravatura, e outras lutas emancipadoras que ocorreram ou estão por ocorrer, em que essa reinterpretação do direito foi precisa.

Deste modo, Derrida vai apontar para a necessidade de se buscar exemplos de "marginalidade em ação" para que se possa negociar ou calcular o incalculável, o que transborda ao direito. Assim deve-se haver uma abertura das fronteiras seguras do campo jurídico frente aos movimentos de politização e emancipação, que demandam redefinições e inter-relações do ético, da moral, do filosófico, do literário, do jurídico, enfim. Assim, a aporia da urgência que barra o horizonte do saber, é uma dificuldade insuperável, mas que se "resolve" com a abertura ou o transbordamento que se discute, se politiza, se calcula para além dos horizontes que se fecham.

Desse modo, a teoria da desconstrução em Derrida encoraja a pluralidade de discursos, - já que não existe uma verdade, a verdade é o nada ou o tudo, o por vir, a justiça ou o próprio movimento de desconstrução, - a fim de disseminar possíveis e novas verdades, para além de uma racionalidade instrumental, de um aprisionamento ou formatação das ações sociais. 
Revista Eletrônica do CEJUR, Curitiba-PR, a. 2, v. 1, n. 3, ago./dez. 2008

Contudo o autor aponta que é possível e preciso criar um sentido num universo de sentidos, não que se fundamente em um saber acumulado, acadêmico, calculado e pautado em inúmeras criteriologias; mas em experiências para além dos horizontes do sujeito, da consciência branca-machista-adulta-possuidora-carnívora. Coloca deste modo, a necessidade de um cálculo sobre o incalculável, ou seja, de atos de estabilização pautados em um verdadeiro compromisso com o Outro $^{31}$.

Assim para pautar a paradoxal busca de abertura e fechamento nas sociedades democráticas (se é que existem de fato), os temas marginais em ação na sociedade, como o aborto, a questão das pesquisas com células-tronco, ou as macro e micropolíticas da droga, dos "sem-teto" e "sem terra" são apontadas como o além dos horizontes. Temas que exigem avanço no campo político e conseqüentemente resignificações no e do jurídico.

\subsubsection{Limites da Teoria da Desconstrução e o aporte da Vida concreta de Enrique Dussel}

Eternizar o presente, subtrair-se à contingência do tempo, com terror ao futuro, é o 'pháthos' de todo grupo dominador. Pelo contrário, o maltratado rosto do beduíno do deserto, a sulcada e escurecida pele do camponês, o intoxicado pulmão do mineiro, em cujo rosto o sol está ausente, estes rostos "aparentemente" feios, quase horríveis para o sistema, são beleza primeira, beleza futura, beleza popular. ${ }^{32}$

No entanto, deve-se apontar que este Outro além dos horizontes do hoje, como coloca Derrida - que pode estar em temas politicamente relevantes - brotam de nãosujeitos segundo o sujeito branco-varão-adulto-possuidor do centro dos horizontes do

${ }^{31}$ Esta fixação do eu frente ao Outro de Emmanuel Lévinas parte da idéia de que a Ética, e não a Ontologia, é a Filosofia primeira. É no face-a-face humano que se irrompe todo sentido. Diante do rosto do Outro, o sujeito se descobre responsável e lhe vem à idéia o Infinito. LEVINAS, Emmanuel. Totalidade e infinito. Lisboa: Edições 70, 1988.

${ }^{32}$ Filosofia da libertação na América Latina. São Paulo: Loyola, [s.d.], p. 50. 


\section{OUTRO PARADIGMA PARA O DIREITO: REFLEXões A PARTIR DA TEORIA DA DESCONSTRUÇÃO DE JAQUES DERRIDA E DA VIDA CONCRETA DE ENRIQUE DUSSEL}

sistema, como coloca Enrique Dussel ${ }^{33}$. São não-participantes muitas vezes destes espaços públicos de discussão, seja por motivos de classe (predominante no Brasil, assim como na maioria dos países chamados de "terceiro mundistas") ${ }^{34}$ ou culturais (povos tradicionais sonegados e negados, que, pode-se em última análise afirmar, negados e sonegados por necessidade deste modo capitalista de produzir e reproduzir o capital em detrimento da vida concreta dos sujeitos - motivos também econômicos e de manutenção de classes).

Portanto quem são os "sujeitos" que promovem a desconstrução para além dos horizontes do hoje? São os magistrados e representantes legislativos? Os educados pelo sistema estatal e privado de ensino? O homem médio social: branco, homem, possuidor, letrado? E quanto às nações geopoliticamente periféricas (África, Ásia, América Latina), aos analfabetos, à classe trabalhadora, à mulher os quais devem continuar economicamente enquanto países-colônia; classe trabalhadora-despossuídailetrada-excluída? Os povos tradicionais, o indigente, o lúmpen, outro que não é Outro, é máscara porque não é viável ser rosto? E quanto àqueles a quem a fala foi castrada, a existência violada, aos não participantes do espaço público? Estes corroboram com o movimento da (des)construção das estruturas sociais, da razão instrumental? Quem são

${ }^{33}$ Com Dussel, pode-se afirmar que: a construção da totalidade econômica - capitalismo monopolista concorrencial -,constitui-se exterioridade - formas não-alienadas de produzir a vida -; a partir da totalização do trabalho enquanto mercadoria lega-se à margem do cotidiano o trabalho enquanto materialização da personalidade ou realização do projeto ontológico -; a partir da totalidade pedagógica - conhecimento científico -, rotula-se de - conhecimento "vulgar"- outras formas de conhecimento; da totalidade machista - a mulher -; a totalidade política - centralidade burocrático representativa indireta -, lega-se à sombra formas - descentralizadas, diretas e participativas de se relacionar com a pólis; para totalidade ambiental - o "não-ser" são as gerações futuras; por fim da totalidade jurídica - monista, individualista, formalista -, a exterioridade se constitui na juridicidade pluralista democrático-participativa. DUSSEL. Filosofia da libertação ..., op. cit.

${ }^{34}$ No caso brasileiro, hoje os $10 \%$ mais ricos da população $\neg$ cerca de 18 milhões de pessoas $\neg$ têm em mãos $45,8 \%$ da riqueza nacional. Na outra ponta, os $10 \%$ mais pobres sobrevivem dividindo entre si $1 \%$ da renda nacional. Atualmente, o Brasil é o $10^{\mathrm{a}}$ mais desigual numa lista com 126 países e territórios, segundo o índice de Gini. Este indicador de desigualdade de renda varia de 0 a 1 , sendo 0 em uma situação na qual toda a população possuísse uma renda equivalente, e 1 se apenas uma pessoa detivesse toda a riqueza do país. No relatório, o índice do Brasil é 0,580, menor que o da Colômbia (0,586, nona no ranking dos piores) e pouco maior que os de África do Sul e Paraguai $(0,578$, empatadas na $11^{\mathrm{a}}$ colocação, aponta o relatório de 2006 do Programa das Nações Unidas para o Desenvolvimento (PNUD). Disponível em: <http://www.pnud.org.br>. Acesso em: 27 maio 2008. 
os participantes?

Parece ser o direito, portanto, algo inaprisionável apenas em norma manipulável pelo Estado, pelo uno, pelo sujeito-possuidor-branco-varão-adulto. Há normatividades criadas há tempos pelas tradições, como há as criadas recentemente em reação à postura violenta do Direito Estatal frente ao Outro, ao distinto, ao que se apresenta para além dos horizontes do vigente. Os considerados não-sujeitos, o nãoser, o não-participante apesar de sonegado e negado pela história institucional está aí, existindo e resistindo, disputando o conteúdo e abrangência dos textos (des) construídos, embora não se tenha consciência sobre estes conflitos encobertos.

Não obstante o processo histórico pedagógico - através da filosofia ${ }^{35}$, das ciências, dos livros e jornais - forjar uma realidade européia-branca-adulta-machista, na tentativa de encobrir o ontológico, o "ser" latino americano, Africano, Asiático, seja praticamente (extermínio, fome, etc.) ou ideologicamente (totalização do processo de conhecimento do centro), este continuou existindo e resistindo historicamente na realidade social e transformando a natureza num processo cultural de sobrevivência, e mesmo que não querendo, esta exterioridade produzida com a afirmação do sistema vigente está incorporada na síntese do que hoje se denomina povo brasileiro, boliviano, peruano, venezuelano etc. ${ }^{36}$ As práticas são silenciadas, sua revelação violada, mas sua existência - apesar de em parte exterminada - está aí, se reproduzindo na realidade histórica.

Assim, pode-se afirmar que o movimento de desconstrução das totalidades fetichizadas do sistema constitui-se em uma importante postura filosóficoepistemológica frente ao fenômeno jurídico, mas se não houver um esforço de "descobrir o encoberto" ao ouvir a voz castrada e violada do não-ser, dos não-sujeitos para o hoje posto, não haverá construção materialmente ética e de compromisso com a

35 "A filosofia clássica de todos os tempos é o acabamento e a realização teórica da opressão prática das periferias, já que é o pensamento que exprime o ser do sistema vigente e central". DUSSEL. Filosofia da libertação ..., p. 15.

\footnotetext{
${ }^{36}$ Ibidem, p. 5.
} 


\section{OUTRo PARAdigma PARA O DiREITO: REFleXões A PARTIR DA TEORIA DA DESCONSTRUÇÃO DE JAQUES DERRIDA E DA VIDA CONCRETA DE ENRIQUE DUSSEL}

justiça. A simples abertura ao devir nada garante.

O que se vêem são movimentos de desconstrução-construção do "mesmo", uma fixação do "mesmo", o que Derrida coloca como a apropriação da desconstrução pelo mais perverso cálculo. O que Enrique Dussel traz neste sentido é a necessidade em se realizar neste movimento, a vida concreta do sujeito ${ }^{37}$ em sua produção, reprodução e desenvolvimento em comunidade. A existência de uma ética material com pretensão verdade é a afirmação de que "toda vida quer viver", e viver bem, viver de forma ótima. O direito como justiça deve perseguir e garantir em seu intenso movimento de (des)construção este momento material sobre o qual se funda a ética - a reprodução e desenvolvimento da vida concreta humana - que é universal e comunitária. $^{38}$

O Outro existe e sua própria existência abala as estruturas do posto, como afirma Dussel" ${ }^{39}$ : "A fome do oprimido é a exterioridade prática ou a transcendentalidade interna mais subversiva contra o sistema. Já que saciar estruturalmente a fome do oprimido é mudar radicalmente o sistema (...). O direito do Outro, do oprimido, do pobre em saciar sua fome não é um direito que se justifique pelo projeto do sistema ou por suas leis."

Tal descobrimento deste Outro possibilita o político, o conflito, a abertura, o devir, enfim a desconstrução para além dos horizontes do sistema, dos significados do que seja a ciência, o político, o direito. Este elemento ético-material da vida concreta desenvolvido pela Filosofia da libertação de Enrique Dussel, inserido nesta preocupação político-epistemológica de Derrida com relação ao movimento da desconstrução, pode oferecer um interessante aporte para os construtores do direito na sua busca aporética por justiça e democracia para além da totalidade paradigmática do

\footnotetext{
${ }^{37}$ DUSSEL. Ética da libertação ..., op. cit.
}

${ }^{38}$ Ao passo que "a vida quer viver" universalmente (todo homem e mulher almejam uma vida boa), cada comunidade convenciona os conteúdos dessa melhor vida; o que para determinada cultura o matar alguém para a continuidade da espécie significa um ato ético material que permite a reprodução e desenvolvimento de uma vida boa; para outras culturas este ato constitui um homicídio.

${ }^{39}$ DUSSEL. Filosofia da libertação ..., p. 48. 
direito hoje reproduzido na prática forense.

\section{CONSIDERAÇÕES FINAIS}

O trabalho procurou perpassar por duas teorias filosóficas que considera extremamente relevantes para o pensar-agir dos construtores do direito a partir de uma racionalidade material, mais colada à dinâmica plural e complexa das realidades concretas. Desta forma, busca aportes filosóficos na teoria desconstrutivista de Jacques Derrida e na Filosofia da libertação de Enrique Dussel, a fim de se tentar modificar a atual postura epistemológica que embasa a prática forense de um direito posto fechado e estático, pronto para por a sociedade em ordem. O que torna o espaço público algo também fechado e apartado da sociedade civil, portanto, privatizado.

A teoria desconstrutivista derridiana traz a assunção das aporias da força da lei, da regra, do saber, desmistificando a necessidade de qualquer fundamento para o direito, o qual se resolve enquanto violência. Desta forma, todo texto que se põe norma ou decisão - ao passo que se fecha para se presentificar, se abre às inesgotáveis re-significações que todo espaço público deve propiciar. Interpretações que variam de acordo com o lugar e com tempo em que estão inseridos os sujeitos-participantes deste espaço público. Mas, pergunta-se, quem são estes sujeitos participantes?

Para encarar esta questão o texto procurou aporte na filosofia da Libertação na América Latina desenvolvida por Enrique Dussel a fim de tomar a discussão desde a realidade concreta específica dos países "terceiro mundistas", como a realidade Latino Americana e especificamente a brasileira. Assim procura-se desenvolver o Outro, o para além dos horizontes do saber ao qual Derrida se remete ao colocar a necessidade do movimento da desconstrução, desde a realidade das vítimas ou dos não-sujeitos, com coloca Dussel. O momento ético material da vida concreta - universal e comunitária - desenvolvido por Dussel em Ética da Libertação pode oferecer importantes reflexões na busca por este Outro paradigma para o direito. Paradigma 


\section{OUTRO PARAdigma PARA O DIREITO: REFLEXões A PARTIR DA TEORIA DA DESCONSTRUÇÃO DE JAQUES DERRIDA E DA VIDA CONCRETA DE ENRIQUE DUSSEL}

este que possa assumir a pluralidade e abertura do fenômeno político-jurídico e afirmar o Outro como ser, o não-ser para os horizontes do hoje como sujeito-participante, agora sim de um espaço público apto ao exercício democrático, à busca da justiça.

\section{REFERÊNCIAS}

DERRIDA, Jacques. Força de lei: o fundamento místico da autoridade. São Paulo: Martins Fontes, 2007.

DUSSEL, Enrique. Ética da libertação - na idade da globalização e da exclusão. Petrópolis: Vozes, 2000.

Filosofia da libertação na América Latina. São Paulo: Loyola, [s.d.].

FARIA, José Eduardo. Eficácia jurídica e violência simbólica: o direito como instrumento de mudança social. São Paulo: EDUSP, 1988.

KOZICKI, Katya. A interpretação do direito e a possibilidade da justiça em Jacques Derrida. In: FONSECA, Ricardo Marcelo (org.). Repensando a teoria do Estado. Florianópolis: Fundação Boiteux, 2005.

LEVINAS, Emmanuel. Totalidade e infinito. Lisboa: Edições 70, 1988.

MACHADO, Antonio Alberto. Ensino jurídico e mudança social. Franca: UnespFHDSS, 2005.

MARQUES NETO,Agostinho Ramalho. Introdução ao estudo do direito: conceito, objeto, método. 2. ed. Rio de Janeiro: Forense, 1990.

<http://www.pnud.org.br>. Acesso em 27 maio 2008.

< http://www.filologia.org.br/viiifelin>. Acesso em 28 maio 2008. 